\title{
Diagnosis and Staging of Breast Cancer: When and How to Use Mammography, Tomosynthesis, Ultrasound, Contrast- Enhanced Mammography, and Magnetic Resonance Imaging
}

\author{
Fiona J. Gilbert and Katja Pinker-Domenig
}

\section{Learning Objectives}

- To understand when and how to use mammography, digital breast tomosynthesis, ultrasound, contrastenhanced mammography, and magnetic resonance imaging for the diagnosis and staging of breast cancer.

- To realize the limitations of each imaging modality.

- To understand the information that can be obtained with each imaging modality and their complementary value in this context.

\subsection{Mammography}

Breast cancer is the most common cause of female cancer deaths in the western world, with early detection of cancer being pivotal for an improved prognosis and survival. Mammography is the mainstay of breast cancer screening and diagnosis [1-3]. Mammography is a two-dimensional image and relies on the identification of morphologic findings that are suspicious for breast cancer (Fig. 13.1). These findings include masses, grouped calcifications, asymmetries, and areas of architectural distortion. A standard screening mammogram consists of mediolateral oblique (MLO) and craniocaudal (CC) views of each breast. The screening exam is intended solely to detect suspicious findings after which the

\footnotetext{
F. J. Gilbert $(\bowtie)$

Department of Radiology, School of Clinical Medicine, University of Cambridge, Cambridge, UK

e-mail: fjg28@medschl.cam.ac.uk

K. Pinker-Domenig

Department of Radiology, Breast Imaging Service, Memorial

Sloan Kettering Cancer Center, New York, NY, USA

e-mail: pinkerdk@mskcc.org
}

woman would return for additional diagnostic views. Diagnostic mammographic views may include spot compression, magnification, rolled, extended views, and true lateral views among others in order to characterize and localize abnormalities. The Breast Imaging Reporting and Data System (BIRADS) was developed by the American College of Radiology in order to standardize terminology describing mammographic findings [4]. The BIRADS atlas also outlines acceptable performance metrics for screening mammography programs such as a cancer detection rate of $\geq 2.5$ cancers $/ 1000$ screens and a recall rate between 5 and 12\%. Performance benchmarks are also available for diagnostic mammography, such as a positive predictive value of biopsy of between 20 and $45 \%$. Randomized controlled trials have found that screening mammography has decreased the mortality for breast cancer by $30 \%$ [1]. However, with a sensitivity of approximately 70\%, mammography has its limitations. Particularly in women with dense breasts, cancers might be occult on mammography [5]. Current recommendations for breast cancer screening in the United States and Europe are somewhat variable. The Society of Breast Imaging, the American College of Radiology, and the National Comprehensive Cancer Network recommend annual screening mammography beginning at the age of 40 years for women at average risk for breast cancer. Due to varying judgments of the benefits and harms of screening, the American College of Obstetricians and Gynecologists guidelines differ from the recommendations issued by the US Preventive Services Task Force, the American Cancer Society, the National Comprehensive Cancer Network, and the American College of Radiology/Society of Breast Imaging (Table 13.1). Women at increased risk for breast cancer (i.e., $\geq 20 \%$ lifetime risk) are recommended to undergo supplemental screening in addition to mammography with breast MRI [6, 7]. Women who are BRCA1/2 gene mutation carriers or who are not tested but have an equivalent risk (with TP53 Li Fraumeni syndrome, AT homozygote or supradiaphragmatic radiother- 

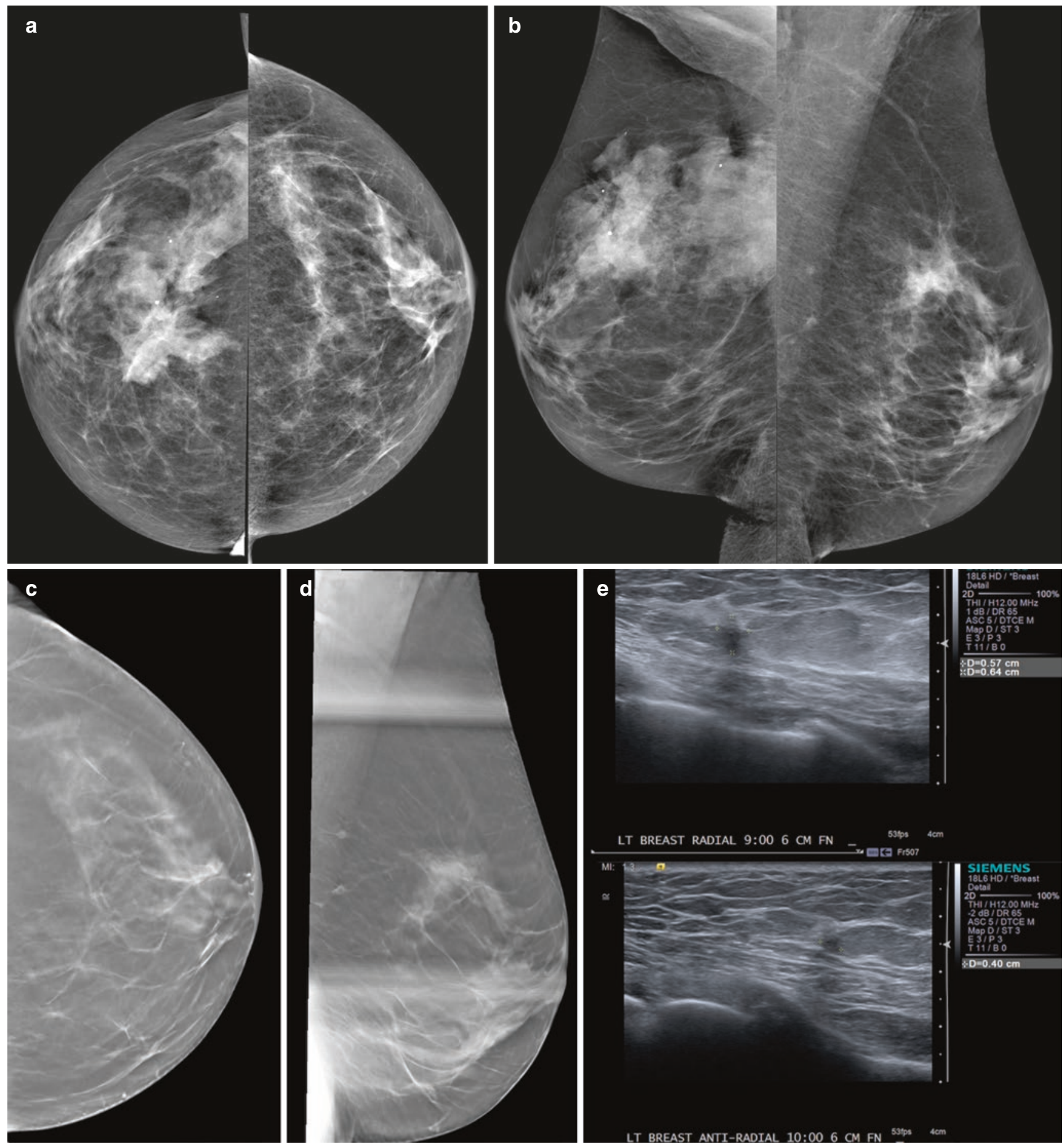

Fig. 13.1 Screen-detected multifocal invasive ductal carcinoma III between the 9 and 10:00 axis of the left breast in a 72-year-old patient with a personal history of right breast cancer, breast conserving therapy and radiation treatment in 1983. (a, b) CC and MLO views: Postsurgical changes are present in the right breast. There are two new irregular shaped and partially spiculated masses in the 9 and 10:00 axis

of the left breast posterior depth which are best appreciated on additional tomosynthesis views CC (c) and ML (d, spot). On targeted ultrasound (e) these correspond to two irregular shaped and marginated hypoechoic masses $(9: 006 \mathrm{~cm}$ from the nipple $0.6 \times 0.5 \mathrm{~cm}, 10: 006 \mathrm{~cm}$ from the nipple $0.4 \times 0.4 \mathrm{~cm}$ )

apy before the age 30 years) are offered annual mammography \pm MRI. In addition, recent breast density legislation in the United States requires that women be informed if they have mammographically heterogeneously dense or extremely dense breasts and that supplemental breast cancer screening be considered. This has led to an increased use of mammog- 
Table 13.1 Recommendations for breast cancer screening in average-risk women

\begin{tabular}{|c|c|c|c|c|c|}
\hline & $\begin{array}{l}\text { UK National Health } \\
\text { Service Breast } \\
\text { Screening } \\
\text { Programme }\end{array}$ & $\begin{array}{l}\text { U.S. Preventive Services } \\
\text { Task Force }\end{array}$ & $\begin{array}{l}\text { American Cancer } \\
\text { Society }\end{array}$ & $\begin{array}{l}\text { National Comprehensive } \\
\text { Cancer Network }\end{array}$ & $\begin{array}{l}\text { American College } \\
\text { of Radiology/ } \\
\text { Society of Breast } \\
\text { Imaging }\end{array}$ \\
\hline $\begin{array}{l}\text { Clinical breast } \\
\text { examination }\end{array}$ & Not recommended & $\begin{array}{l}\text { Insufficient evidence to } \\
\text { recommend for or against }\end{array}$ & Not recommended & $\begin{array}{l}\text { Recommend every 1-3 } \\
\text { years for women } 25-39 \\
\text { years and annually for } \\
\text { women } 40 \text { years and } \\
\text { older }\end{array}$ & Not recommended \\
\hline $\begin{array}{l}\text { Mammography } \\
\text { initiation age }\end{array}$ & $\begin{array}{l}\text { Offer starting at age } \\
50 \text { years }\end{array}$ & $\begin{array}{l}\text { Recommend at age } 50 \text { years } \\
\text { Age } 40-49 \text { years: decision to } \\
\text { start screening } \\
\text { mammography before age } 50 \\
\text { years should be an individual } \\
\text { one }\end{array}$ & $\begin{array}{l}\text { Offer at ages } 40-45 \\
\text { years } \\
\text { Recommend at age } 45 \\
\text { years }\end{array}$ & Recommend at age 40 & $\begin{array}{l}\text { Recommend at age } \\
40\end{array}$ \\
\hline $\begin{array}{l}\text { Mammography } \\
\text { screening } \\
\text { interval }\end{array}$ & Three yearly & Biennial & $\begin{array}{l}\text { Annual for women } \\
\text { aged } 40-54 \text { years } \\
\text { Biennial with the } \\
\text { option to continue } \\
\text { annual screening for } \\
\text { women } 55 \text { years or } \\
\text { older }\end{array}$ & Annual & Annual \\
\hline $\begin{array}{l}\text { Mammography } \\
\text { stop age }\end{array}$ & $\begin{array}{l}\text { Continue until age } \\
70 \text { years } \\
\text { Beyond age } 70 \\
\text { years, women may } \\
\text { continue to attend } \\
\text { every } 3 \text { years }\end{array}$ & $\begin{array}{l}\text { The current evidence is } \\
\text { insufficient to assess the } \\
\text { balance of benefits and harms } \\
\text { of screening mammography } \\
\text { women } 75 \text { years and older }\end{array}$ & $\begin{array}{l}\text { When life expectancy } \\
\text { is less than } 10 \text { years }\end{array}$ & $\begin{array}{l}\text { When severe } \\
\text { comorbidities limit life } \\
\text { expectancy to } 10 \text { years } \\
\text { or less }\end{array}$ & $\begin{array}{l}\text { When life } \\
\text { expectancy is less } \\
\text { than 5-7 years }\end{array}$ \\
\hline
\end{tabular}

raphy supplemented with whole-breast screening ultrasound in women with dense breast tissue [8].

\subsubsection{Staging with Mammography}

Mammography, together with ultrasound and MRI as detailed below, is used to detect and characterize lesions found at screening and to evaluate symptomatic women. In patients with breast cancer, diagnostic mammography, often in conjunction with specialized views - latero-medial (LM) and mediolateral (ML), extended CC, magnification, spot compression, and other views - is used to determine lesion size and location as well as to image the surrounding tissue and lymph nodes [9]. Diagnostic mammography is often tailored to the specific problem. For example, in a woman with suspicious mammographic calcifications, magnification views are necessary to evaluate the extent of calcifications (Fig. 13.2). If calcifications are associated with an asymmetry or mass, further evaluation with ultrasound is warranted to search for a solid mass that may indicate an invasive component.

\section{Key Point}

- Mammography is a two-dimensional image and relies on the identification of morphologic findings that are suspicious for breast cancer. Mammography is the mainstay of breast cancer screening and diagnosis.

\subsection{Digital Breast Tomosynthesis}

Digital breast tomosynthesis (DBT) images are created from repeated exposure of the breast tissue from different angles and data processing interpolated into multiple slices typically $0.5 \mathrm{~mm}$ thick through the breast tissue. Many retrospective and prospective studies have demonstrated that this technique is acceptable to women, increases the radiation dose by an average of $20 \%$, and increases cancer detection by approximately $15-30 \%$ while reducing recall rates by $15-20 \%$ by decreasing overlapping shadows mimicking breast cancer [10]. While the technique is excellent for 

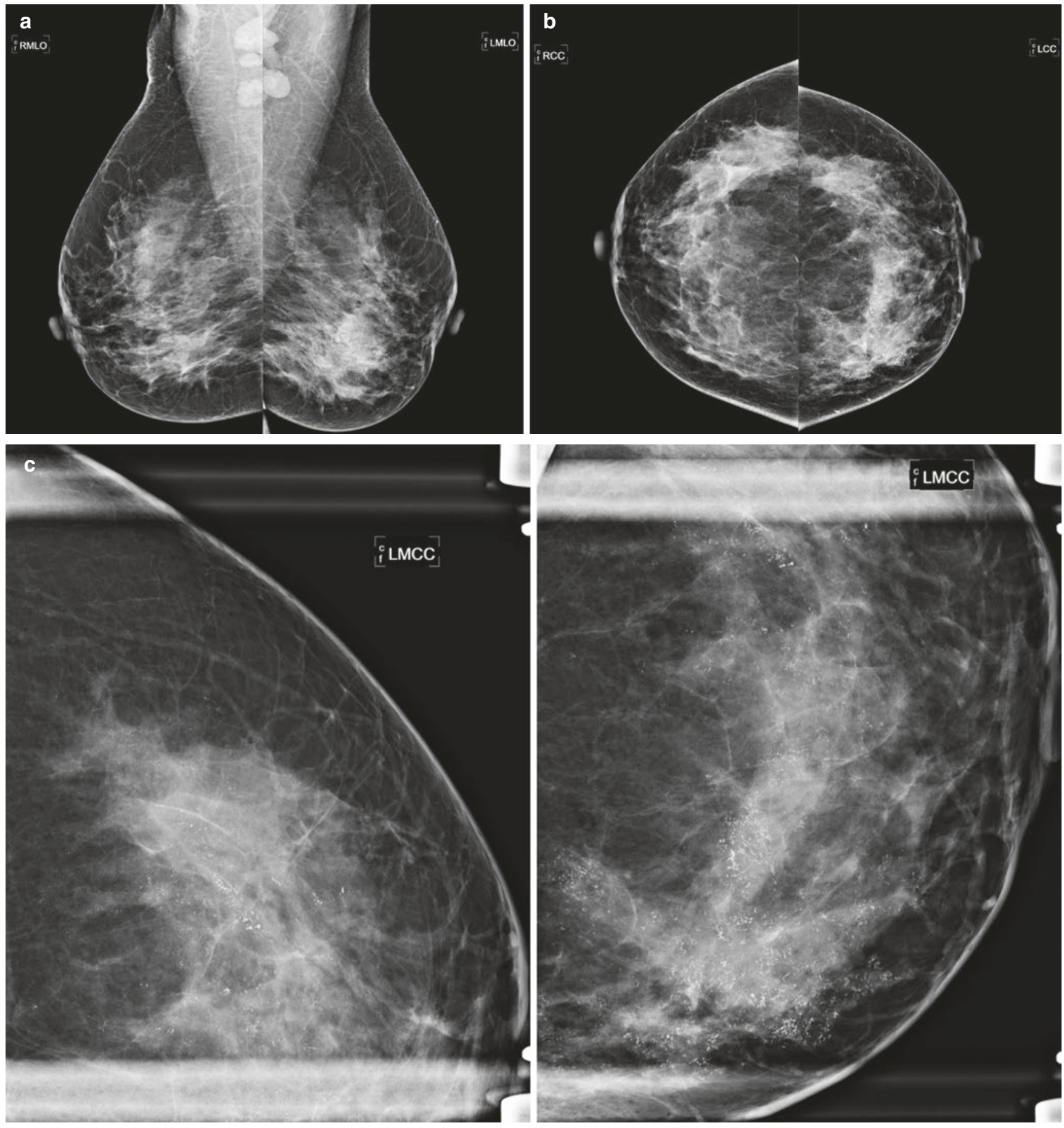

Fig 13.2 Multicentric invasive ductal carcinoma III and ductal carcinoma in situ high grade in a 54-year-old patient presenting with a palpable area of concern in the left breast for diagnostic mammography. CC and MLO views (a, b) and left magnification views CC (c) and ML (d). In the right breast there are no suspicious mass or tumor calcifica-

tions present. In the left breast there are pleomorphic microcalcifications spanning both the lower inner and outer quadrant. In addition, there is an enlarged axillary lymph node, which was confirmed to be metastatic 

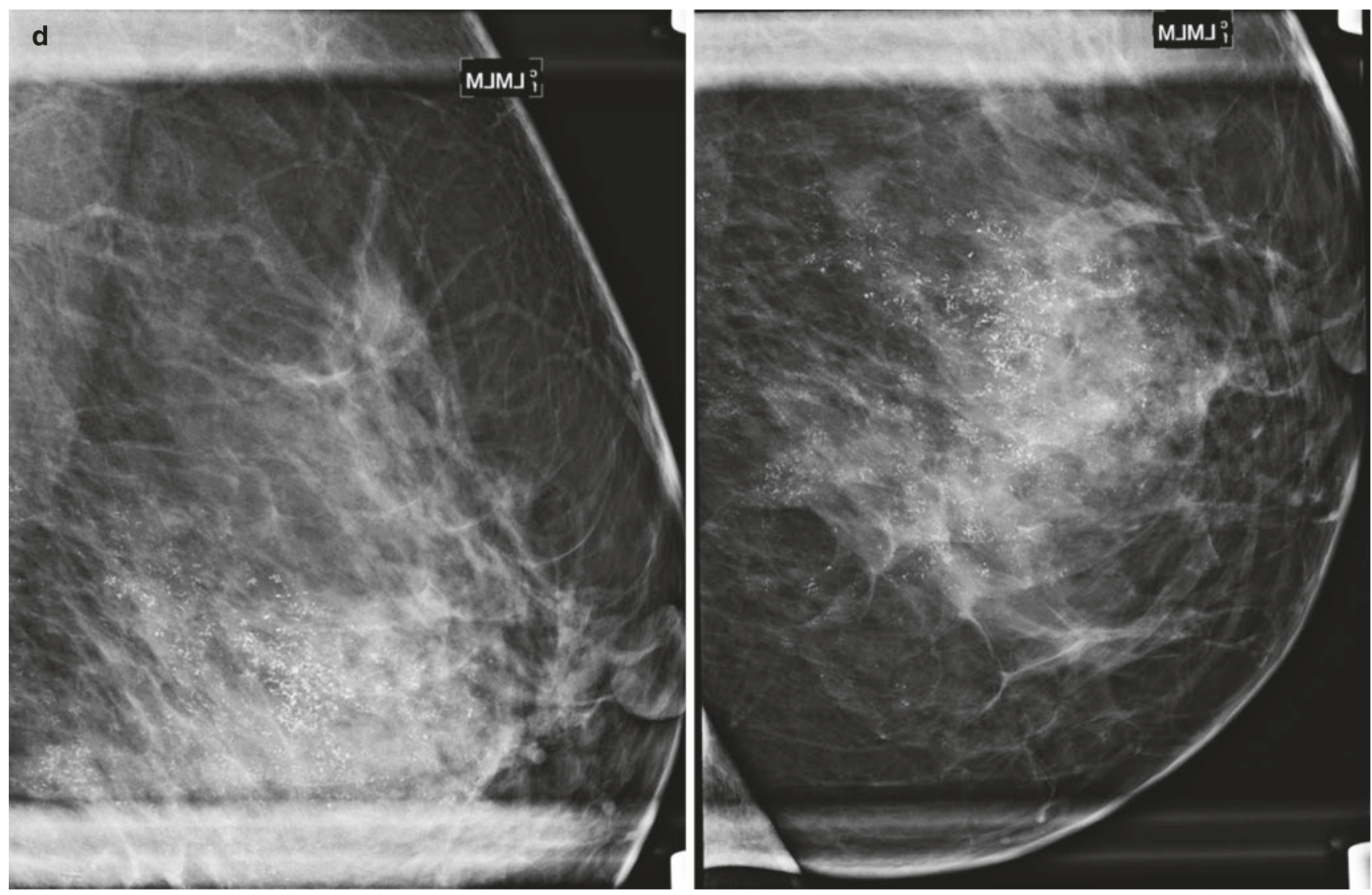

Fig 13.2 (continued)

assessing soft tissue masses, architectural distortion, and asymmetries, the conspicuity and analysis of microcalcification were not improved [11]. However, recently, due to faster processing techniques manufacturers have been able to analyze all pixels instead of "binning" (combining pixels with the effect of reducing resolution) the data to reduce processing time. This means that fine calcification can now be more clearly identified with improved sensitivity and specificity.

DBT has been shown to be particularly useful in women with mixed to dense breast tissue (BIRADS B \& C) but is not advantageous in women with very dense breast tissue. DBT is now increasingly used in the clinic either on its own with a 2D composite image or in conjunction with a standard 2D full-field digital mammography (FFDM) image. The advantage of using DBT is that the need for additional views such as the coned view or other supplemental techniques is no longer required [12]. In a recent meta-analysis, 17 studies were found where DBT was compared with 2D mammography in a screening setting. The pooled incremental cancer detection rate was 1.6 cancers/1000 screens compared with 2D FFDM with an overall absolute reduction in recall rates of $2.2 \%$. However, there were differences between European and US-based studies with European studies showing a higher cancer detection rate of 2.4 cancers $/ 1000$ screens and a $0.5 \%$ increase in recall rates and US studies showing a reduction in the recall rates due the higher recall rates initially [13].

In the symptomatic setting, DBT has been found to have improved diagnostic accuracy compared with 2D mammography and improved reader confidence in distinguishing benign from malignant lesions and is more accurate in assessing tumor size and at identifying multifocal disease [14]. Techniques are also now available for image-guided biopsy using DBT to guide targeting.

\section{Key Point}

- DBT has the potential to overcome the primary limitation of standard two-dimensional mammography, a masking effect due to overlapping fibroglandular breast tissue, improving diagnostic accuracy by differentiating benign and malignant features, and increasing lesion conspicuity, particularly in dense breasts. 


\subsection{Contrast-Enhanced Mammography}

Contrast-enhanced mammography (CEM) is an emerging technology in breast imaging. CEM allows both a morphologic evaluation comparable to routine digital mammography and a simultaneous assessment of tumor neovascularity as an indicator of malignancy. Contrast-enhanced spectral mammography (CESM) acquires a low $\mathrm{kV}$ image and a high $\mathrm{kV}$ image simultaneously before and after the injection of iodinated contrast. Retrospective studies comparing CESM with standard 2D mammography show significant improvement in the sensitivity and specificity for detecting breast carcinomas with CESM; the sensitivity of CESM is $93-100 \%$ compared with $71.5-93 \%$ for mammography and increases the specificity from 42 to $87.7 \%$. The patient populations in all these studies were either symptomatic patients or patients recalled to assessment after an abnormal screening mammogram $[15,16]$.
In women with heterogeneously or dense breasts (BIRADS C \& D), small occult cancers can be seen with CESM due to increased vascularity from tumor angiogenesis. In women with dense breasts, CESM is one of several supplementary techniques that can be used to avoid overlooking cancer (Fig. 13.3). The low-dose image is virtually as good as a 2D FFDM image and has the same resolution as a conventional image. However, microcalcification due to low-grade DCIS is often not visualized on the subtracted image of CESM.

The disadvantage of this contrast examination is that approximately the same dose of iodinated contrast is injected intravenously, and sensitivity reactions can occur at the same rate as with computed tomography (CT) examinations. This means that CESM must be performed in a center with resuscitation facilities in place, and caution must be exercised in patients with impaired renal function, patients with allergies, and in the elderly.
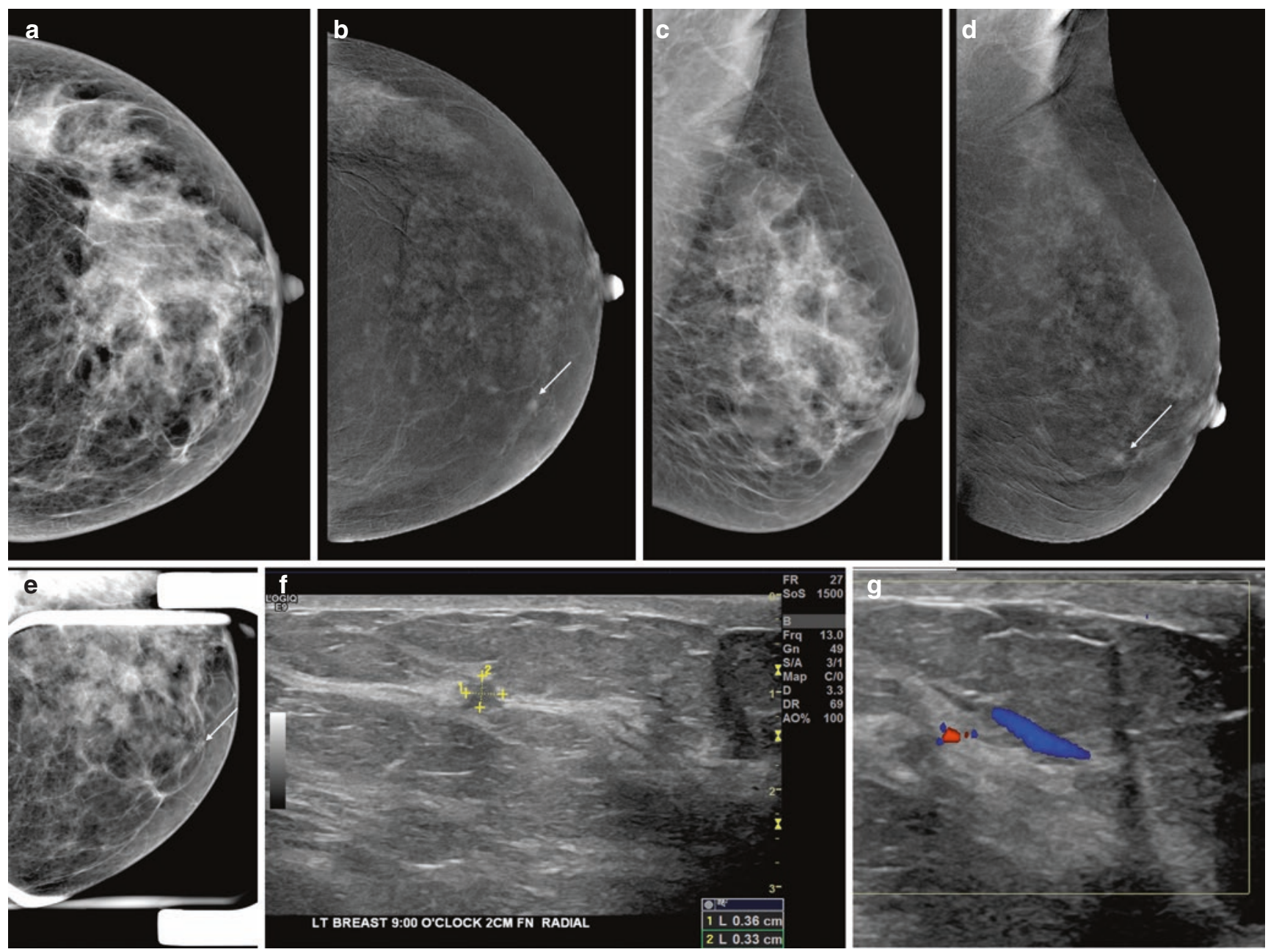

Fig. 13.3 Invasive ductal carcinoma II in a 49-year-old patient who underwent contrast-enhanced mammography with a personal history of right breast cancer and mastectomy and reduction mammoplasty on the left. CC and MLO views (a, c), contrast-enhanced CC and MLO views (b, d), left CC spot compression view and diagnostic targeted ultra- sound (f, g with color doppler). On mammography, left lower inner focal asymmetry that does not efface on spot compression correlates to a $0.4 \mathrm{~cm}$ enhancing mass on CEM. Targeted ultrasound shows an irregular shaped and marginated hypoechoic mass with vascularization 
The diagnostic accuracy in younger women and in those with dense breasts in the symptomatic setting is improved compared with 2D mammography [17].

\subsubsection{Staging with CESM}

A major advantage of CESM is that the ability to see additional foci of disease is enhanced hugely and, in many studies, it is comparable to MRI. Jochelson et al. found equal sensitivity between MRI and CESM for detecting the index cancer, although MRI was less sensitive for detecting additional tumor foci [18]. Lee-Felker et al. found that MRI had slightly higher sensitivity for the index lesion but equal sensitivity for detecting additional tumor foci [19]. Overall both studies showed that CESM had a significantly improved positive predictive value and specificity compared with MRI, as well as fewer false-positive interpretations. This means that once a cancer is suspected on imaging at the clinic visit, a CESM examination can be performed which has almost comparable sensitivity and specificity to staging breast MRI.

Key Point

- CEM allows both a morphologic evaluation comparable to routine digital mammography and a simultaneous assessment of tumor neovascularity as an indicator of malignancy similar to MRI. CEM has an improved sensitivity and increases the specificity compared with mammography.

\subsection{Ultrasound}

Handheld ultrasound (US) has improved enormously over the last 20 years with markedly improved resolution and rapid image processing. While it is rarely used as a primary diagnostic tool, US is used in the majority of patients presenting with a clinical symptom as an adjunctive tool to further analyze a mammographic abnormality to determine whether a soft tissue mass is solid or cystic and to differentiate benign from malignant masses. It is also used when there is a negative mammographic examination, but the patient has a clinical symptom or palpable abnormality. The procedure is acceptable to patients, is safe with no ionizing radiation, but is operator dependent. The drawback for conventional US is that in breast tissue with extensive fibrocystic disease and shadowing, small tumors can be overlooked especially if they are invasive lobular disease. Ductal carcinoma in situ (DCIS) can be picked up now due to the improved resolution as microcalcification can produce a speckled pattern but DCIS with no calcification is difficult to detect.

Whole-breast US or Automated Breast US (ABUS) is a technique that is rapidly gaining acceptance. This technique requires the operator to undertake three positions with a flat panel US plate of each breast. The images are reconstructed to produce a $3 \mathrm{D}$ examination of the breast. This technique is showing promise in many clinical trials and may become the examination of choice for women with dense breasts in whom a supplemental examination is justified. A third of the United States, France, and Belgium have introduced supplemental imaging techniques such as US for women with BIRADS C \& D breast density although in all cases this additional examination is insurance or self-funded. The literature supports the use of the supplemental imaging with studies reporting an additional 4 cancers/1000 screens when used with annual or 2-yearly screening. While the drawback for screening US has traditionally been that it had high recall rates ranging from 10 to $30 \%$, a recent publication from Sweden has shown more promising results with ABUS with recall below $2.5 \%$ while good sensitivity is retained [20].

A most valuable aspect of US is the ability to rapidly undertake an image-guided biopsy. This can be done safely, in a timely manner at the first visit to the clinic and has a degree of accuracy without any precautions save checking for a bleeding diathesis.

\subsubsection{Staging with US}

US is widely used to confirm a diagnosis of cancer and to look for additional disease in the breast which is found in up to $20 \%$ cases. Additional disease is more often found toward the nipple and in the same quadrant as the index tumor.

Assessment of the axilla to look for abnormal lymph nodes is a very popular approach. The short axis diameter of axillary nodes is less than $5 \mathrm{~mm}$ in size, but in reality there is a large variation in normal lymph node size. Hence, the more reliable indicators of disease are abnormal shape (rounded), loss of echogenicity of the hilum, thickened cortex by more than $3 \mathrm{~mm}$, or irregular lobulated cortex. When proving malignancy prior to surgery, US-guided core biopsies are undertaken.

US is also used extensively as a second-look tool in patients with abnormalities found on MRI particularly when the features are not diagnostic.

Lastly, US is used in localization techniques prior to surgery including the placing of a guide wire into the cancer to aid surgical procedure. This can be done accurately and efficiently under US guidance.

\section{Key Point}

- US is widely used to confirm a diagnosis of cancer, to look for additional disease in the breast, for image-guided breast biopsy and localization, assessment of the axilla, and as a second-look tool in patients with abnormalities found on MRI. 


\subsection{Magnetic Resonance Imaging}

Magnetic resonance imaging (MRI) is established valuable technique in breast imaging with multiple clinical indications, such as preoperative staging, response assessment to neoadjuvant therapy, scar vs. recurrence, assessment of breast implant integrity, evaluation of patients with cancer of unknown primary, and screening of high-risk patients [21, 22]. Dynamic contrast-enhanced magnetic resonance
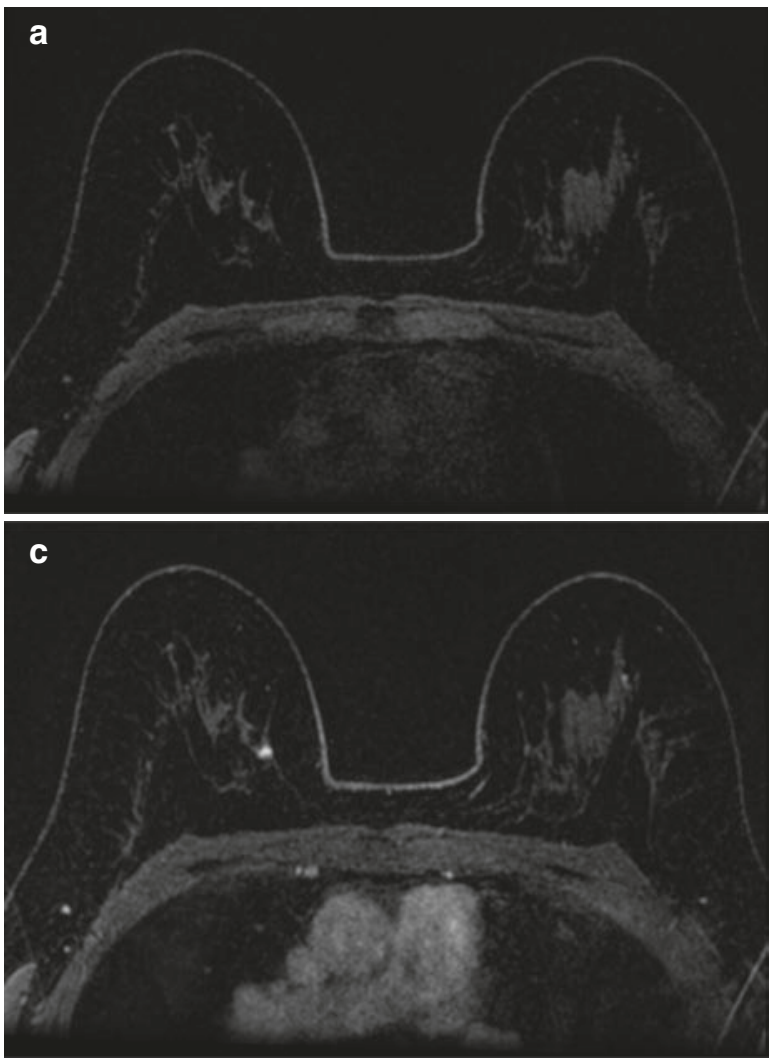

e

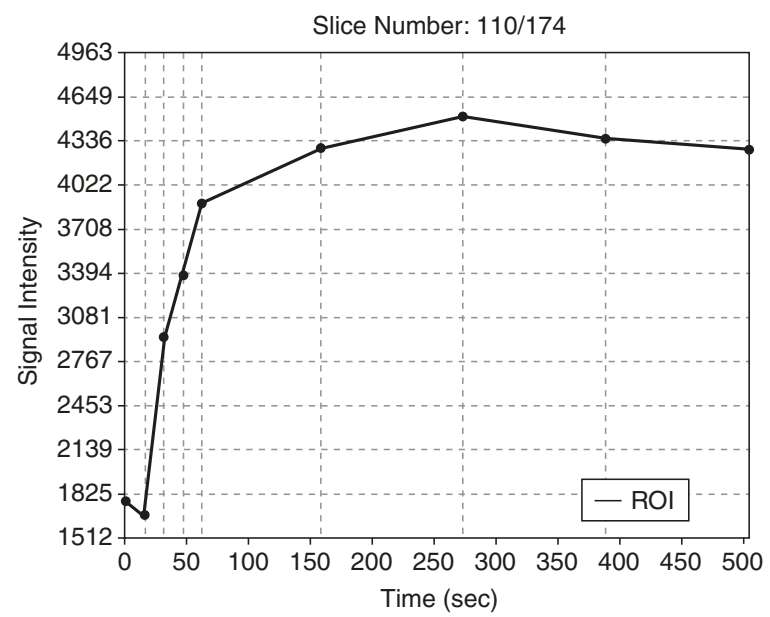

Fig. $13.40 .4 \mathrm{~cm}$ invasive ductal carcinoma III medially in the right breast of a high-risk 51-year-old patient undergoing screening MRI. DCE-MRI (a, b, c) and MIP (d) shows round circumscribed mass imaging (DCE-MRI) provides high-resolution breast morphology and enhancement kinetics to depict angiogenesis as a tumor-specific feature. Undisputedly DCE-MRI is the most sensitive modality for breast cancer detection with a pooled sensitivity of $93 \%$; in terms of specificity, it has good pooled specificity of $71 \%$ [23]. In women who are at high risk for breast cancer, several studies have demonstrated that DCE-MRI is the superior screening modality compared with conventional imaging techniques [6, 7]
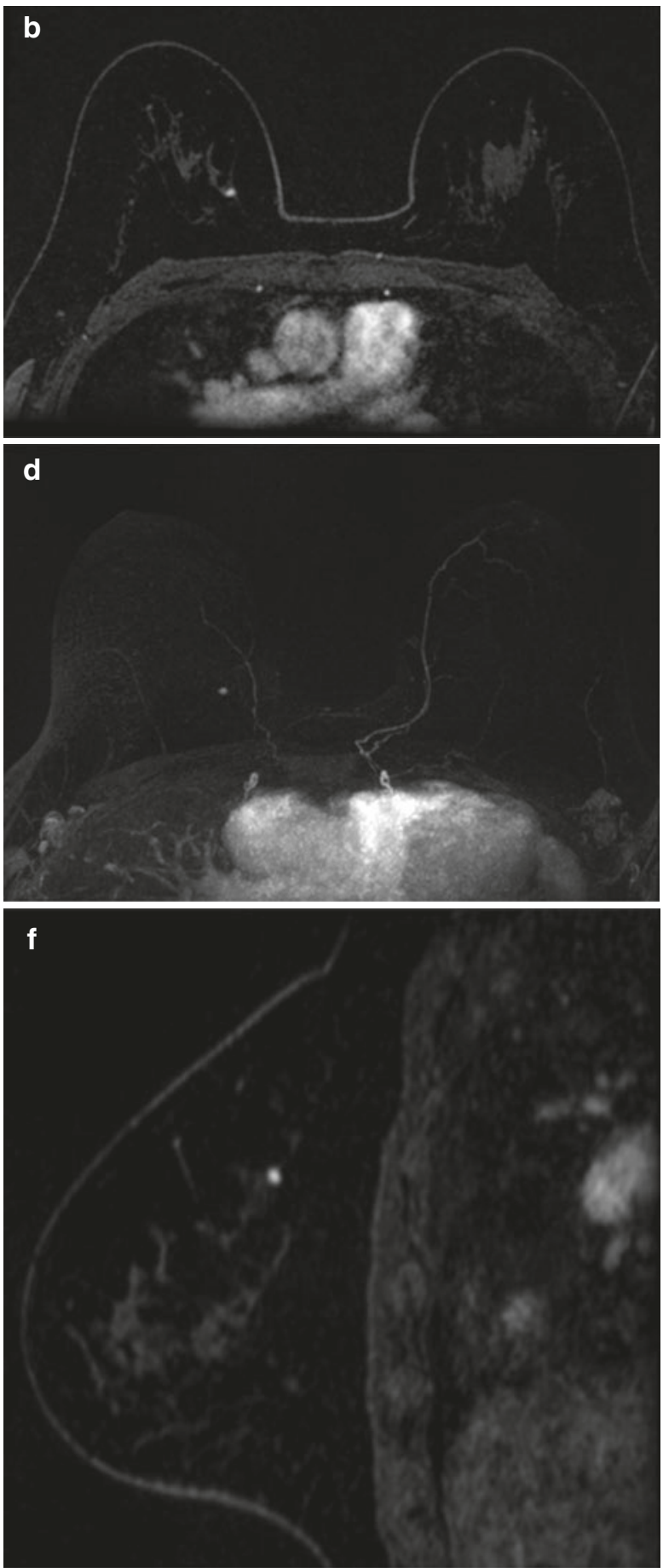

with initial fast (b)/delayed plateau (c) enhancement signal intensity graph (e) sagittal view (f). Screening mammography and ultrasound were negative 
(Fig. 13.4). Therefore, adjunct screening with DCE-MRI is recommended for women with a high $(>20 \%)$ lifetime risk of breast cancer [21, 22, 24], facilitating earlier cancer detection and reducing interval cancers [25-27] in this population. This has also prompted a most recent similar recommendation for its use in women with an intermediate ( $>15 \%$ ) lifetime risk of breast cancer [28]. To overcome limitations in DCE-MRI specificity and assess more functional data, additional MRI parameters can be combined with DCE-MRI; this approach is known as multiparametric MRI (MP MRI). In this context, diffusion-weighted imaging (DWI) with apparent diffusion coefficient (ADC) mapping has emerged as the most robust and valuable parameter with a reported sensitivity of up to $96 \%$ for breast cancer detection and a specificity of up to $100 \%$ for breast tumor characterization [29, 30] and is therefore increasingly implemented in clinical routine.
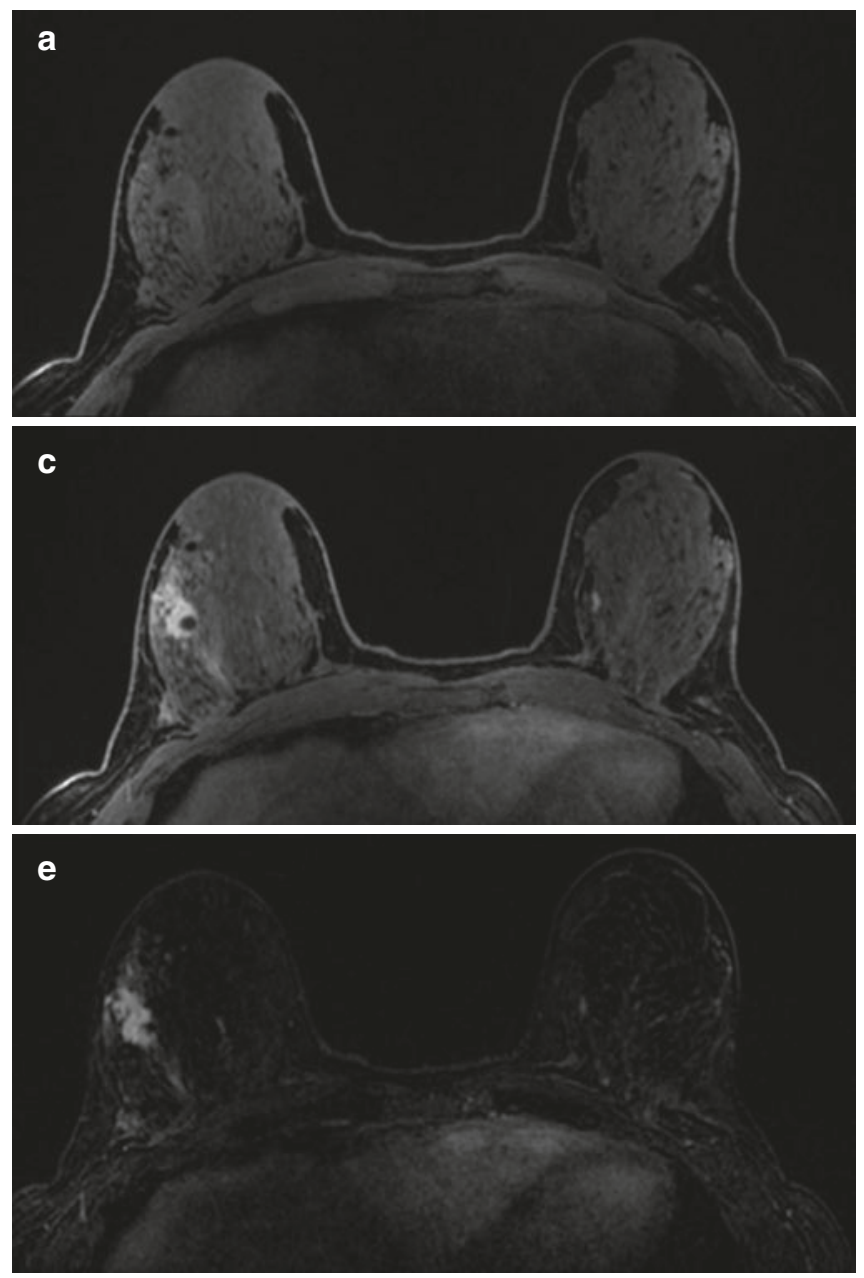

Fig. 13.5 MRI for staging of extent of disease in a 50-year-old patient with an invasive ductal carcinoma III with extensive intraductal component (EIC). On DCE-MRI (a, b), subtractions (d) and MIP (e). In the 9:00 axis mid depth there is a round irregular marginated mass with initial fast (b, f)/delayed plateau (c, f) enhancement measuring $1.4 \times 1.4$ $\times 1.1 \mathrm{~cm}$ with susceptibility artifact from clip marker. Extending from

\subsubsection{Staging with MRI}

In patients with a biopsy-proven breast cancer, MRI may be used for the assessment of disease extent and detection of additional lesions in the same (multifocal) or different quadrants (multicentric) or in the contralateral breast potentially impacting patient management (Figs. 13.5 and 13.6). In this context DCE-MRI is more useful than mammography and US when staging multifocal and multicentric disease or when DCIS is present (Fig. 13.5) [31]. In addition, numerous studies have shown that DCE-MRI is superior to mammography and US for assessment of tumor size, yet there is still over- and underestimation in up to $15 \%$ of patients $[31,32]$. Although an improved preoperative disease assessment can be expected to improve surgical outcomes, currently the evidence is controversial $[33,34]$ with respect to breast cancer histopathology and other studies. There is a good body of
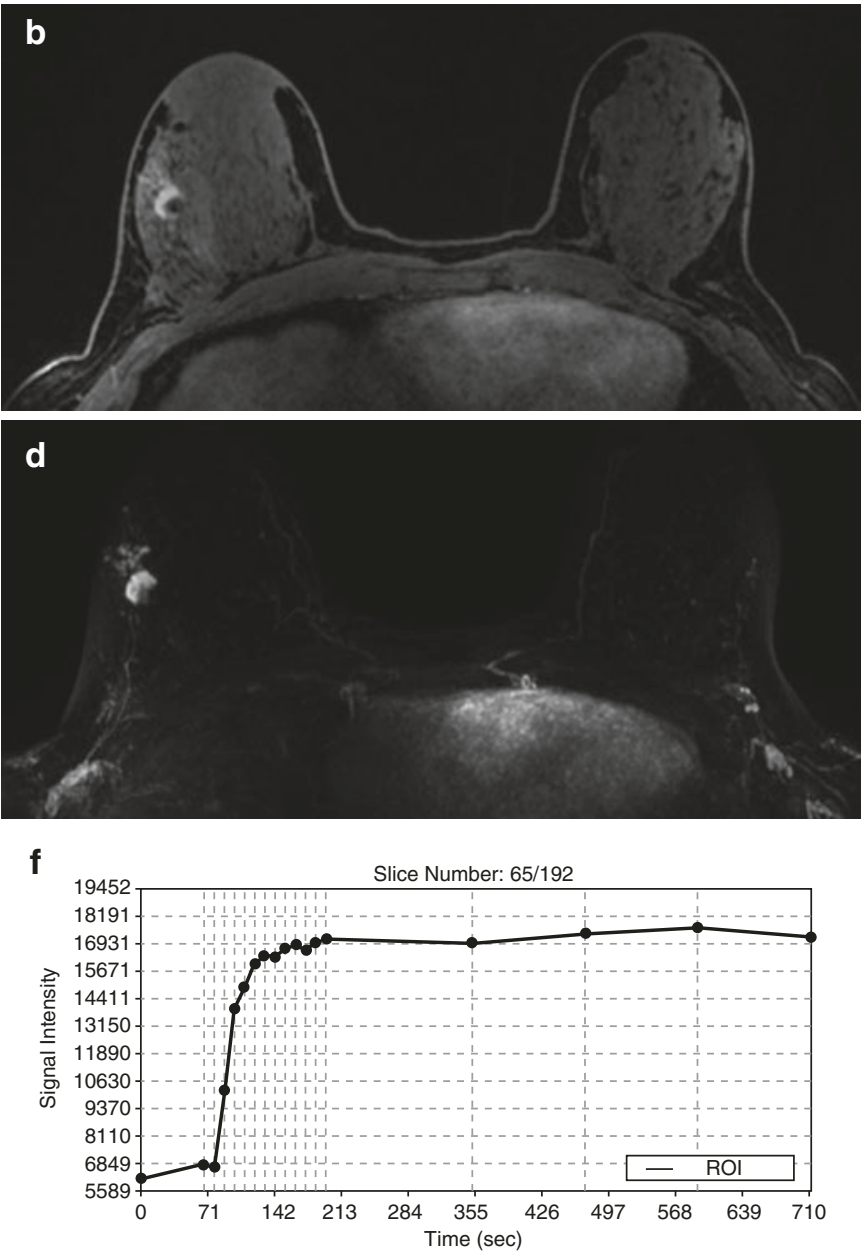

the index cancer into the anterior third of the breast there is a heterogeneous segmental non-mass enhancement representing the EIC. The index cancer and the contiguous non-mass enhancement span an area of approximately $3.8 \times 1.6 \times 1.5 \mathrm{~cm}$. The non-mass enhancement engulfs a biopsy marker from a prior benign breast biopsy 

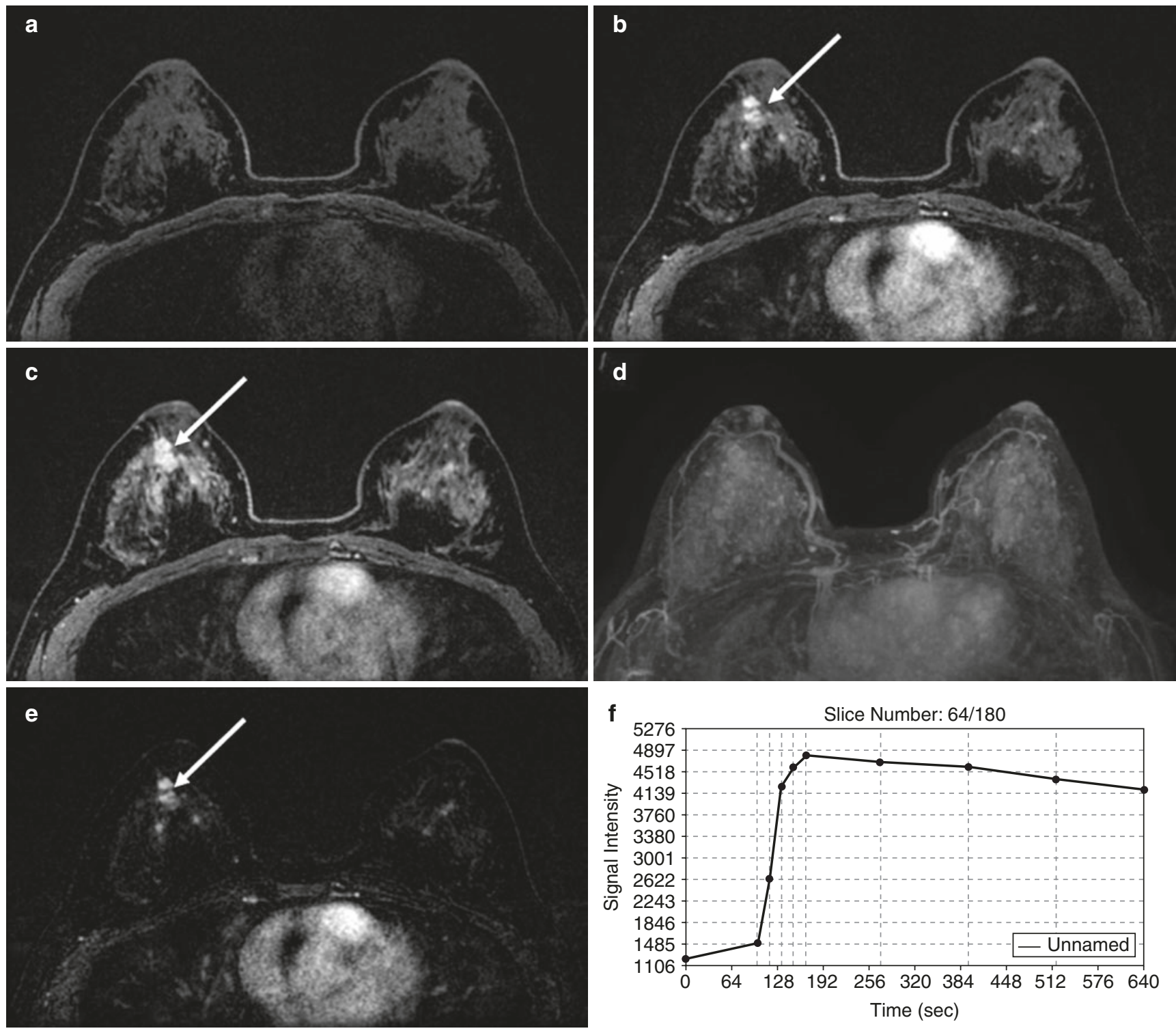

Fig. 13.6 Ductal carcinoma in situ (DCIS) intermediate grade, atypical ductal hyperplasia (ADH) and lobular carcinoma in situ classic type in 46-year-old patient with a history of right breast $\mathrm{ADH}$ and status post excisional biopsy undergoing screening MRI. Screening mammography and targeted second look sonography were negative. MRI-guided

evidence that staging MRI has a value in invasive lobular cancer (ILC), a histopathological breast cancer subtype that is typically underestimated by mammography and US, and reduces re-excision rates in ILC, ranging from 11 to $18 \%$ $[35,36]$. It has to be noted that presurgical MRI often detects additional suspicious lesions that are occult on mammography and US, thus potentially leading to more extensive surgery. Histopathological verification is therefore mandatory before changes of treatment strategies are recommended based on these additional findings. The primary goal of surgery is to reduce tumor burden and is usually part of a sophis-

biopsy of the non-mass enhancement in the right breast retroareolar area shows right DCIS, ADH and LCIS. High resolution DCE-MRI $(\mathbf{a}-\mathbf{c})$, subtractions (e) and MIP (d) show in the early phase unique areas of non-mass enhancement with initial fast/delayed persistent enhancement (f)

ticated treatment strategy that includes radiation therapy, chemotherapy, and hormonal therapy. Although additional cancerous lesions detected by DCE-MRI might be effectively treated with these therapies, to date, there is a lack of evidence that preoperative DCE-MRI improves overall or disease-free survival [37].

DCE-MRI may also detect cancers that were occult on mammography and/or sonography in the contralateral breast in approximately 3\% of women with unilateral cancer detected by mammography or US [38]. The detection of these initially unsuspected tumors may have a greater impact on 
patient outcomes than the detection of additional ipsilateral tumor foci as these would not be treated with concomitant radiation therapy. Although patient prognosis is determined by the size and grade of the index cancer, early detection of second cancers may be associated with a slight increase in survival, especially in patients younger than 50 years old [22]. Another indication of pretreatment breast MRI is as a problem-solving tool when tumor size differs significantly among imaging modalities or clinical examination and to evaluate eligibility for partial breast radiation therapy [21].

\section{Key Point}

- DCE-MRI is the most sensitive modality for breast cancer detection with excellent sensitivity and good specificity. MRI is used for the assessment of disease extent and detection of additional lesions. DCE-MRI is more useful than mammography and US when staging multifocal and multicentric disease or when DCIS is present.

\subsection{Concluding Remarks}

In conclusion, imaging plays a pivotal role in breast cancer detection and staging and helps in guiding treatment decisions. Imaging modalities for diagnosis and staging of breast cancer comprise mammography, DBT, ultrasound, CEM, and MRI. Whereas mammography is the mainstay of breast cancer screening and diagnosis, other imaging modalities such as DBT and CEM have emerged with the potential to overcome limitations in sensitivity and specificity adding valuable information in breast cancer staging. US is widely used to confirm a breast cancer diagnosis, to look for additional disease and for image-guided breast biopsy and localization, staging of the axilla, and as a second-look tool in patients with suspicious findings on MRI. DCE-MRI remains the most sensitive modality for breast cancer detection with excellent sensitivity and good specificity and is more useful than mammography and US for the assessment of disease extent and detection of additional disease. Each imaging modality has its limitations and advantages and therefore may be used in conjunction to facilitate an optimal breast cancer staging and treatment.

\section{Take-Home Messages}

- Mammography is the mainstay of breast cancer screening and diagnosis.

- Breast US is widely used to confirm a diagnosis of breast cancer, to look for additional disease in the breast and for image-guided breast interventions.
- DBT, CEM, and MRI increase cancer detection, especially in women with dense breasts at increased risk of cancer.

- MRI of the breast is superior to other imaging modalities for the assessment of disease extent and detection of additional disease.

\section{References}

1. Tabar L, Vitak B, Chen TH, Yen AM, Cohen A, Tot T, et al. Swedish two-county trial: impact of mammographic screening on breast cancer mortality during 3 decades. Radiology. 2011;260(3):658-63.

2. Hellquist BN, Duffy SW, Abdsaleh S, Bjorneld L, Bordas P, Tabar L, et al. Effectiveness of population-based service screening with mammography for women ages 40 to 49 years: evaluation of the Swedish Mammography Screening in Young Women (SCRY) cohort. Cancer. 2011;117(4):714-22.

3. Moss SM, Wale C, Smith R, Evans A, Cuckle H, Duffy SW. Effect of mammographic screening from age 40 years on breast cancer mortality in the UK Age trial at 17 years' follow-up: a randomised controlled trial. Lancet Oncol. 2015;16(9):1123-32.

4. D'Orsi CJ, Sickles EA, Mendelson EB, Morris EA, et al. ACR BI-RADS ${ }^{\circledR}$ atlas, breast imaging reporting and data system. 5 th ed. Reston, VA: American College of Radiology; 2013.

5. Pisano ED, Gatsonis C, Hendrick E, Yaffe M, Baum JK, Acharyya S, et al. Diagnostic performance of digital versus film mammography for breast-cancer screening. N Engl J Med. 2005;353(17):1773-83.

6. Riedl CC, Luft N, Bernhart C, Weber M, Bernathova M, Tea MK, et al. Triple-modality screening trial for familial breast cancer underlines the importance of magnetic resonance imaging and questions the role of mammography and ultrasound regardless of patient mutation status, age, and breast density. J Clin Oncol. 2015;33(10):1128-35.

7. Krammer J, Pinker-Domenig K, Robson ME, Gonen M, BernardDavila B, Morris EA, et al. Breast cancer detection and tumor characteristics in BRCA1 and BRCA2 mutation carriers. Breast Cancer Res Treat. 2017;163(3):565-71.

8. Tagliafico AS, Calabrese M, Mariscotti G, Durando M, Tosto S, Monetti F, et al. Adjunct screening with tomosynthesis or ultrasound in women with mammography-negative dense breasts: interim report of a prospective comparative trial. J Clin Oncol. 2016;

9. Lee SC, Jain PA, Jethwa SC, Tripathy D, Yamashita MW. Radiologist's role in breast cancer staging: providing key information for clinicians. Radiographics. 2014;34(2):330-42.

10. Gilbert FJ, Tucker L, Young KC. Digital breast tomosynthesis (DBT): a review of the evidence for use as a screening tool. Clin Radiol. 2016;71(2):141-50.

11. Gilbert FJ, Tucker L, Gillan MG, Willsher P, Cooke J, Duncan KA, et al. Accuracy of digital breast tomosynthesis for depicting breast cancer subgroups in a UK retrospective reading study (TOMMY Trial). Radiology. 2015;277(3):697-706.

12. Gilbert FJ, Selamoglu A. Personalised screening: is this the way forward? Clin Radiol. 2018;73(4):327-33.

13. Marinovich ML, Hunter KE, Macaskill P, Houssami N. Breast cancer screening using tomosynthesis or mammography: a meta-analysis of cancer detection and recall. J Natl Cancer Inst. 2018;110(9):942-9.

14. Michell MJ, Batohi B. Role of tomosynthesis in breast imaging going forward. Clin Radiol. 2018;73(4):358-71. 
15. Lobbes MB, Lalji U, Houwers J, Nijssen EC, Nelemans PJ, van Roozendaal L, et al. Contrast-enhanced spectral mammography in patients referred from the breast cancer screening programme. Eur Radiol. 2014;24(7):1668-76.

16. Lalji UC, Houben IP, Prevos R, Gommers S, van Goethem M, Vanwetswinkel S, et al. Contrast-enhanced spectral mammography in recalls from the Dutch breast cancer screening program: validation of results in a large multireader, multicase study. Eur Radiol. 2016;26(12):4371-9.

17. Tennant SL, James JJ, Cornford EJ, Chen Y, Burrell HC, Hamilton LJ, et al. Contrast-enhanced spectral mammography improves diagnostic accuracy in the symptomatic setting. Clin Radiol. 2016;71(11):1148-55.

18. Jochelson MS, Dershaw DD, Sung JS, Heerdt AS, Thornton C, Moskowitz CS, et al. Bilateral contrast-enhanced dual-energy digital mammography: feasibility and comparison with conventional digital mammography and MR imaging in women with known breast carcinoma. Radiology. 2013;266(3):743-51.

19. Lee-Felker SA, Tekchandani L, Thomas M, Gupta E, AndrewsTang D, Roth A, et al. Newly diagnosed breast cancer: comparison of contrast-enhanced spectral mammography and breast MR imaging in the evaluation of extent of disease. Radiology. 2017;285(2):389-400.

20. Wilczek B, Wilczek HE, Rasouliyan L, Leifland K. Adding 3D automated breast ultrasound to mammography screening in women with heterogeneously and extremely dense breasts: Report from a hospital-based, high-volume, single-center breast cancer screening program. Eur J Radiol. 2016;85(9):1554-63.

21. Sardanelli F, Boetes C, Borisch B, Decker T, Federico M, Gilbert FJ, et al. Magnetic resonance imaging of the breast: recommendations from the EUSOMA working group. Eur J Cancer. 2010;46(8):1296-316.

22. Mann RM, Balleyguier C, Baltzer PA, Bick U, Colin C, Cornford E, et al. Breast MRI: EUSOBI recommendations for women's information. Eur Radiol. 2015;25(12):3669-78. https://doi.org/10.1007/ s00330-015-3807-z.

23. Zhang L, Tang M, Min Z, Lu J, Lei X, Zhang X. Accuracy of combined dynamic contrast-enhanced magnetic resonance imaging and diffusion-weighted imaging for breast cancer detection: a metaanalysis. Acta Radiol. 2016;57(6):651-60.

24. Saslow D, Boetes C, Burke W, Harms S, Leach MO, Lehman $\mathrm{CD}$, et al. American Cancer Society guidelines for breast screening with MRI as an adjunct to mammography. CA Cancer J Clin. 2007:57(2):75-89.

25. Sardanelli F, Podo F, Santoro F, Manoukian S, Bergonzi S, Trecate $\mathrm{G}$, et al. Multicenter surveillance of women at high genetic breast cancer risk using mammography, ultrasonography, and contrastenhanced magnetic resonance imaging (the high breast cancer risk Italian 1 study): final results. Investig Radiol. 2011;46(2):94-105.

26. Kuhl CK, Schrading S, Leutner CC, Morakkabati-Spitz N, Wardelmann E, Fimmers R, et al. Mammography, breast ultrasound, and magnetic resonance imaging for surveillance of women at high familial risk for breast cancer. J Clin Oncol. 2005;23(33):8469-76.

27. Passaperuma K, Warner E, Causer PA, Hill KA, Messner S, Wong JW, et al. Long-term results of screening with magnetic resonance imaging in women with BRCA mutations. Br J Cancer. 2012;107(1):24-30.

28. Monticciolo DL, Newell MS, Moy L, Niell B, Monsees B, Sickles EA. Breast cancer screening in women at higher-than-average risk: recommendations from the ACR. J Am Coll Radiol. 2018;15(3. Pt A):408-14.

29. Dorrius MD, Dijkstra H, Oudkerk M, Sijens PE. Effect of b value and pre-admission of contrast on diagnostic accuracy of 1.5-T breast DWI: a systematic review and meta-analysis. Eur Radiol. 2014;24(11):2835-47.

30. Chen X, Li WL, Zhang YL, Wu Q, Guo YM, Bai ZL. Meta-analysis of quantitative diffusion-weighted MR imaging in the differential diagnosis of breast lesions. BMC Cancer. 2010;10:693.

31. Esserman L, Hylton N, Yassa L, Barclay J, Frankel S, Sickles E. Utility of magnetic resonance imaging in the management of breast cancer: evidence for improved preoperative staging. J Clin Oncol. 1999;17(1):110-9.

32. Boetes C, Mus RD, Holland R, Barentsz JO, Strijk SP, Wobbes T, et al. Breast tumors: comparative accuracy of MR imaging relative to mammography and US for demonstrating extent. Radiology. 1995; 197(3):743-7.

33. Turnbull L, Brown S, Harvey I, Olivier C, Drew P, Napp V, et al. Comparative effectiveness of MRI in breast cancer (COMICE) trial: a randomised controlled trial. Lancet. 2010;375(9714):563-71.

34. Gonzalez V, Sandelin K, Karlsson A, Aberg W, Lofgren L, Iliescu $\mathrm{G}$, et al. Preoperative MRI of the breast (POMB) influences primary treatment in breast cancer: a prospective, randomized, multicenter study. World J Surg. 2014;38(7):1685-93.

35. Mann RM, Loo CE, Wobbes T, Bult P, Barentsz JO, Gilhuijs KG, et al. The impact of preoperative breast MRI on the re-excision rate in invasive lobular carcinoma of the breast. Breast Cancer Res Treat. 2010;119(2):415-22.

36. Houssami N, Turner R, Morrow M. Preoperative magnetic resonance imaging in breast cancer: meta-analysis of surgical outcomes. Ann Surg. 2013;257(2):249-55.

37. Ryu J, Park HS, Kim S, Kim JY, Park S, Kim SI. Preoperative magnetic resonance imaging and survival outcomes in T1-2 breast cancer patients who receive breast-conserving therapy. J Breast Cancer. 2016;19(4):423-8.

38. Pediconi F, Catalano C, Roselli A, Padula S, Altomari F, Moriconi $\mathrm{E}$, et al. Contrast-enhanced MR mammography for evaluation of the contralateral breast in patients with diagnosed unilateral breast cancer or high-risk lesions. Radiology. 2007;243(3):670-80.

Open Access This chapter is licensed under the terms of the Creative Commons Attribution 4.0 International License (http://creativecommons. org/licenses/by/4.0/), which permits use, sharing, adaptation, distribution and reproduction in any medium or format, as long as you give appropriate credit to the original author(s) and the source, provide a link to the Creative Commons license and indicate if changes were made.

The images or other third party material in this chapter are included in the chapter's Creative Commons license, unless indicated otherwise in a credit line to the material. If material is not included in the chapter's Creative Commons license and your intended use is not permitted by statutory regulation or exceeds the permitted use, you will need to obtain permission directly from the copyright holder. 